\title{
Imperfectives and Plurality
}

\author{
Marcelo Ferreira \\ Massachusetts Institute of Technology
}

\section{Introduction}

Imperfectivity, understood as a semantic notion, has been described in the informal literature on tense and aspect as expressing the idea that an event, state, or habit is ongoing. For instance, the English progressive sentence in (1) says that, at the time when I saw Mary, there was an ongoing event of her crossing Vassar Street, and the 'simple present' sentence in (2) says that Mary is currently in the habit of smoking:

(1) Mary was crossing Vassar Street (when I saw her).

(2) Mary smokes.

In an interval-based semantics, the intuitions mentioned above can be formalized by using the relation of temporal inclusion. According to this view, someone who uttered (1) would assert that the time at which I saw Mary is included in a time interval at which she crossed Vassar Street. Similarly, someone who uttered (2) would assert that the utterance time is included in an interval corresponding to the duration of a habit of Mary smoking. But what does it mean for a time interval to be an interval at which Mary crosses the street? And what exactly constitutes a habit of Mary smoking? Suppose we answer the first question by saying that an interval at which Mary crosses the street is an interval corresponding to a complete event of Mary crossing the street, beginning when she is on one side of the street and starts crossing, and finishing only when she gets to the other side. Then, we would face the problem of explaining why a sentence like (3) below is judged true, when uttered at a time right after Mary started crossing the street, despite the fact that she never got to the other side:

Mary was crossing Vassar Street, when a bus hit her.

A way out of this puzzle is to introduce a modal component as part of the meaning of progressive sentences with the effect that the utterer does not commit himself to the existence in the actual world of a complete event of the sort described by the sentence. A proponent of this view is then left with the task of spelling out what kind of modality is involved in these sentences. ${ }^{1}$

What about habituals? I should say from the beginning that I will only be dealing here with what I will call 'simple habituals'. Habituality has often been discussed in connection with issues related to the expression of genericity in natural languages, the former being considered as a special case of the letter (see Krifka et al. (1995), Cohen (1999), Greenberg (2003), inter alia, for discussion). 
A common view is that habitual sentences are interpreted as tripartite structures involving a silent habitual (or generic) operator with a universal, or quasiuniversal, quantificational force, whose restrictor is identified with the help of adverbial clauses, topic-focus structure, and contextual information, as exemplified in (4) below (the sentences in (5) provide informal paraphrases):

a. When there is a party, Mary dyes her hair.

b. Mary [writes $]_{F}$ to her mother. [In a discussion about how Mary and her mother communicate.]

a. Every time there is a party, Mary dyes her hair.

b. Every time Mary and her mother communicate, Mary writes to her.

Simple habituals on the other hand do not come with adverbial clauses, do not require any special focus marking, and can be uttered out of the blue and still sound natural and informative. Some examples are provided in (6):
a. John smokes.
b. Mary dyes her hair.
c. Sally jogs.

For cases like these, it is not clear at all what could play the role of the restrictor of the habitual quantifier. ${ }^{2}$ For instance, there are so many different circumstances under which a certain person can smoke, that it seems impossible to identify a set of situations without being too vague ('every appropriate time to smoke, Mary smokes') or just trivial ('every time Mary smokes, she smokes'). One can smoke just because he or she feels like it from time to time, or every day at noon, or maybe because someone is forcing him or her to do so. It does not matter. A sentence like 'Mary smokes' can be uttered without the intention to link situations of Mary smoking to any other kind of situation, and a hearer does not feel compelled or invited to accommodate any kind of situation either. What seems to be at issue here is the existence of situations in which Mary smokes. ${ }^{3}$

Suppose then that we answer our second question above about what a habit is by saying that a habit of Mary smoking is a sequence of time intervals at which she smokes. A problem arises here that is similar to the one we discussed in connection to (3). Imagine Mary died a couple of minutes after someone had uttered (2), and that in fact she used to smoke before she died. One would not conclude from the facts that the speaker was wrong when he uttered (2), despite the fact that the time of that utterance followed the final time interval at which Mary smoked, and therefore was not included within an ongoing sequence of time intervals at which Mary smokes. Once again, a way out of this problem is to include a modal component in habitual sentences, so that someone who utters (2) can avoid committing himself to the existence in the actual world of future events of Mary smoking. ${ }^{4}$

In this paper, I subscribe to the view that (simple) habitual and continuous readings connected with imperfectivity have both a temporal and a modal 
component. However, I will go further and defend a stronger position, namely, that continuous and habitual readings share the same temporal and the same modal ingredients. The basis for this unification will be an interval semantics that I will develop, which is based on a structured temporal domain containing both singular and plural intervals, coupled with a modal semantics along the lines developed by Paul Portner for the English progressive (Portner (1998)). At the core of the ideas to be presented below is the suggestion that plural intervals are the formal counterpart of the notion 'sequence of intervals' informally employed above. $^{5}$

The paper is organized as follows: in section 2, I present the relevant details of the structured temporal domain I have in mind. In section 3, I suggest that verb phrases combine with number morphemes forming constituents denoting sets of singular or plural time intervals. In section 4, I discuss the temporal component of imperfectivity and propose a unified semantics for continuous and habitual readings. In section 5, I analyze some crosslinguistic data involving imperfective constructions and argue that the aspectual operators involved in them display a sensibility to 'number' (singular/plural) that is very similar to what is observed with determiners in the nominal domain. In section 6, I present Portner's work on the modal semantics of progressive sentences in English, and argue that it can be extended to habitual sentences. The upshot is that the logical forms underlying continuous and habitual readings become identical, modulo the number specification of the time intervals involved. Section 7 is a brief summary.

\section{The Algebra of Time Intervals}

The definition of a time interval can be built upon the notion of time point. The set of time points together with the relation $<$ (precedence) form what is called a dense linear order. A time interval $I$ can be defined as a convex set of time points, that is, a set such that for any time points $\mathrm{p}_{\mathrm{x}}, \mathrm{p}_{\mathrm{y}}, \mathrm{p}_{\mathrm{z}}$, if $\mathrm{p}_{\mathrm{x}}$ and $\mathrm{p}_{\mathrm{y}}$ belong to $I$, and $\mathrm{p}_{\mathrm{x}}<\mathrm{p}_{\mathrm{z}}<\mathrm{p}_{\mathrm{y}}$, then $\mathrm{p}_{\mathrm{z}}$ also belongs to $I$. Intuitively, convex intervals correspond to continuous portions in a time line. I call them singular intervals. In addition to singular intervals, I will assume that $\mathrm{D}_{\mathrm{i}}$, the domain of all time intervals, also contain plural intervals. I take the set of plural intervals $\left(\mathrm{I}_{\mathrm{pl}}\right)$ to correspond to the set formed by closing off the set of singular intervals $\left(\mathrm{I}_{\mathrm{sg}}\right)$ under union and then removing all members of $\mathrm{I}_{\mathrm{sg}}$. As a consequence, plural intervals are not convex. In fact, they can be viewed as sequences of non-overlapping singular intervals. This is so, because the union of two overlapping convex intervals is also a convex interval, therefore also a member of $\mathrm{I}_{\mathrm{sg}}$, and not of $\mathrm{I}_{\mathrm{pl}}$. As an illustration, consider the singular intervals $i_{1}$ and $i_{2}$ in the diagrams below.

(7)

a.

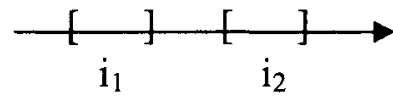

b.

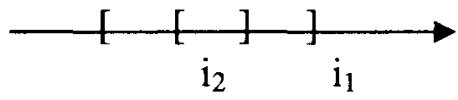


According to the definition of plural intervals just given, since the union of $i_{1}$ and $i_{2}$ belongs to $I_{s g}$ in (7b) but not in (7a), it belongs to $I_{p l}$ in (7a), but not in (7b).

Once we have assumed the existence of both singular and plural intervals, we have to redefine the meaning of certain relations between intervals, such as, precedence and inclusion, extending them to cases including pluralities. They are given below:

Right Boundary/Left Boundary

A time point $p$ is the right/left boundary of an interval $i$ iff $p$ belongs to $i$, and for every time point $p^{\prime}$, if $p^{\prime}$ belongs to $i$, then $p^{\prime} \leq p / p \leq p^{\prime}$.

i-precedence

An interval $i$ i-precedes an interval $i$ ' iff the right boundary of $i$ precedes the left boundary of $i$.

\section{i-inclusion}

An interval $i$ is i-included $\left(\subseteq_{\mathrm{i}}\right)$ in an interval $i$ ' iff the left boundary of $i$ ' precedes the left boundary of $i$, and the right boundary of $i$ precedes the right boundary of $i$.

As far as singular intervals are concerned, the definitions above are quite intuitive, so the interval corresponding to March/2001 i-precedes the interval corresponding to August/2001, and is i-included in the interval corresponding to the first semester of 2001. Now, consider what happens when plural intervals enter the picture. Let $i_{1}$ correspond to March/2001, $i_{2}$ to August/2001, and $i_{3}$ to the plurality January/2001 $\oplus$ May/2001. According to (10), $i_{1}$ is $i$-included in $i_{3}$, since $i_{3}$ 's left boundary precedes $i_{1}$ 's left boundary, and $i_{1}$ 's right boundary precedes $i_{3}$ 's right boundary. Notice that the fact that the time points belonging to $i_{1}$ do not belong to any part of $i_{3}$ is irrelevant. Less surprisingly, according to (9), $i_{3} i$-precedes $i_{2}$, since $i_{3}$ 's right boundary precedes $i_{2}$ 's left boundary. These definitions will become relevant when we discuss the semantics of aspectual operators later in the paper.

\section{Verb Phrases and Plural Intervals}

In this paper, I will assume a version of an interval-based semantics, according to which the denotations of verbs have a temporal argument in addition to whatever individual arguments they have in standard logical renditions of verb meaning. I will assume that the temporal argument is the outermost one and that after a verb combines with its other arguments (if any), the resultant verbal projection (which I will label as VP) denotes (a characteristic function of) a set of time intervals. ${ }^{6}$ Take, for example, the verb 'dye' in a sentence like (11). According to what I just said, we have:

Mary dyed her hair. 


$$
\llbracket \text { dye } \rrbracket=\lambda x \cdot \lambda y \cdot \lambda t . y \text { dyed } x \text { at } t
$$

$$
\llbracket[\text { vp Mary dye her hair }] \rrbracket=\lambda t \text {. Mary dye her hair at } \mathrm{t}
$$

Now, imagine Mary dyed her hair for the first time three years ago, and after that she dyed it twice, one two years ago, and another one last year. Let us call those time intervals $i_{1}, i_{2}$, and $i_{3}$, respectively. Under this scenario, and assuming sshe will never dye her hair again, the denotation of the (bare) VP 'Mary dye her hair' would be the set $\left\{i_{1}, i_{2}, i_{3}\right\}$.

A natural question at this point is whether verb phrase denotations can contain pluralities or not. In other words, one could ask whether verb denotations allow for pluralities as their temporal arguments or not. My answer is yes. I assume that any verb phrase can have both singular and plural intervals in its extension. Thus, in our scenario above where Mary dyed her hair three times in the past, and $i_{1}, i_{2}$, and $i_{3}$ are the intervals corresponding to the exact duration of the events, if we assume that she will never dye her hair again, a speaker who knows the meaning of the verb 'dye' and is aware of the relevant facts will automatically know that (14) is true:

$$
\llbracket[v p \text { Mary dye her hair }] \rrbracket=\left\{i_{1}, i_{2}, i_{3}, i_{1} \oplus i_{2}, i_{1} \oplus i_{3}, i_{2} \oplus i_{3}, i_{1} \oplus i_{2} \oplus i_{3}\right\}
$$

Bare VPs then combine with number morphemes (singular and plural), whose job is to select the relevant members (singular or plural intervals) of the sets denoted by these VPs.

$$
\mathrm{VP}_{\mathrm{sg}}=\left[\begin{array}{ll}
\mathrm{sg} & \mathrm{VP}
\end{array}\right] \quad \mathrm{VP}_{\mathrm{pl}}=\left[\begin{array}{ll}
\mathrm{pl} & \mathrm{VP}
\end{array}\right]
$$

$$
\begin{aligned}
& \llbracket \mathrm{sg} \rrbracket=\lambda \mathrm{P} . \lambda \mathrm{t} . \mathrm{P}(\mathrm{t})=1 \& \mathrm{t} \text { is singular } \\
& \llbracket \mathrm{pl} \rrbracket=\lambda \mathrm{P} \cdot \lambda \mathrm{t} . \mathrm{P}(\mathrm{t})=1 \& \mathrm{t} \text { is plural } \\
& \llbracket \mathrm{VP}_{\mathrm{sg} / \mathrm{p} 1} \rrbracket=\lambda \mathrm{t} . \llbracket \mathrm{VP} \rrbracket(\mathrm{t})=1 \& \mathrm{t} \text { is singular/plural }
\end{aligned}
$$

In the scenario above:

$$
\begin{aligned}
& \text { a. } \llbracket V P_{s g} \rrbracket=\left\{i_{1}, i_{2}, i_{3}\right\} \\
& \text { b. } \llbracket V P_{p l} \rrbracket=\left\{i_{1} \oplus i_{2}, i_{1} \oplus i_{3}, i_{2} \oplus i_{3}, i_{1} \oplus i_{2} \oplus i_{3}\right\}
\end{aligned}
$$

With this much as background, in the next section, we turn to the role played by the aspectual operator responsible for bringing imperfectivity to the meaning of the sentences we started with in the introduction.

\section{The Imperfective Operator}

As a starting point, assume that aspectual operators are modifiers in the following sense: they are functions taking a set of intervals as their input and returning another set of intervals as their output. As far as temporal semantics is concerned, 
the main job of aspectual operators is the introduction of relations between time intervals in the logical representation of sentences (cf. Klein (1994)). In sentences with a single layer of aspectuality, these relations hold between the interval corresponding to the temporal specification of the clause (past/present/future), and an interval belonging to the denotation of the verb phrase. A typical clause skeleton will then look like (18): ${ }^{7}$

\section{$[\mathrm{TP} T$ [AspP Asp [VP-sg/pl sg/pl VP $]]]$}

I will start by encoding the semantics of imperfectivity in a morpheme, which I will call Imp. The main job of this morpheme is to introduce the inclusion relation between intervals, as shown in the lexical entry in (19):

$$
\llbracket \operatorname{Imp} \rrbracket=\lambda P_{<i \triangleright} . \lambda t . \exists t^{\prime}: t^{\prime} \supseteq t \& P\left(t^{\prime}\right)=1
$$

Before looking at a concrete instance of an English sentence containing this morpheme, consider the logical forms in (20) and (21).:

\section{[TP past $_{1}$ [AspP Asp [VP-sg sg [VP John paint the house ]]]]}

$\left[{ }_{\mathrm{TP}}\right.$ past $_{1}$ [AspP Asp [VP-pl pl [VP John paint the house ]]]]

Now, imagine the following scenario: Last year, John painted his house once every month. He always started on the $15^{\text {th }}$ and finished on the $17^{\text {th }}$ of each month. Call the time intervals within each month at which John painted the house $\mathrm{i}_{1}, \mathrm{i}_{2}, \ldots, \mathrm{i}_{12}$. According to what $\mathrm{I}$ said in the previous section, and assuming these were the only occasions in which John painted the house, the extension of the bare VP in (20) and (21)is (22):

$$
\llbracket V P \rrbracket=\left\{i_{1}, i_{2}, i_{1} \oplus i_{2}, i_{3}, i_{3} \oplus i_{2} \oplus i_{3}, \ldots, i_{1} \oplus i_{2} \oplus i_{3} \oplus \ldots \oplus i_{12}\right\}
$$

Given the semantics of Imp above, the truth-conditions for in (20) and (21) should be as in (23) and (24), respectively:

$$
\begin{aligned}
& \llbracket \mathrm{TP} \rrbracket^{\mathrm{g}}=1 \text { iff } \exists \mathrm{t}^{\prime}: \mathrm{t}^{\prime} \supseteq \mathrm{g}(1) \& \mathrm{t}^{\prime} \text { is singular \& PAINT(j,h,t') }=1 \\
& \llbracket T P \rrbracket^{\mathrm{g}}=1 \text { iff } \exists \mathrm{t}^{\prime}: \mathrm{t}^{\prime} \supseteq \mathrm{g}(1) \& \mathrm{t}^{\prime} \text { is plural \& PAINT(j,h,t') }=1
\end{aligned}
$$

Now, assume that Past $_{1}$ refers to June $16^{\text {th }}$. Then (20) should be true, since $i_{6}$, for instance, verifies the formula embedded under the existential quantifier in (23). What if Past $_{1}$ refers to June $20^{\text {th }}$ ? Now (20) should be false, since there is no interval in the denotation of $\mathrm{VP}_{\mathrm{sg}}$ that includes June $20^{\text {th }}$. The situation changes with (21). If Past $_{1}$ refers to June $20^{\text {th }},(21)$ is true, since $i_{5} \oplus i_{7}$, for instance, verifies the formula embedded under the existential quantifier in (24). We need to invoke a plural interval this time, but that is fine, since the denotation of $\mathrm{VP}_{\mathrm{pl}}$ includes plural intervals. Finally, if past $_{1}$ refers to June $16^{\text {th }},(21)$ is still true, but not 
because this interval is included in $i_{6}$, but because it is included in plural intervals, such as $i_{5} \oplus i_{7}$. The conclusion is that logical forms containing Imp can express not only the existence of an on-going event at a certain time, but also the existence of on-going sequences of (two or more) events of John painting the house. The choice will depend on whether Imp combines with singular or plural VPs.

One can imagine more specialized versions of Imp, in which this operator selects for either sets of singularities $\left(\mathrm{P}_{\mathrm{sg}}\right)$ or sets of pluralities $\left(\mathrm{P}_{\mathrm{pl}}\right)$ as its first argument. ${ }^{8}$ As a consequence, only singular or plural intervals are quantified over in the logical representations of sentences containing these operators:

$$
\begin{aligned}
& \llbracket \mathrm{Imp}_{\mathrm{sg}} \rrbracket=\lambda \mathrm{P}_{\mathrm{sg}} \cdot \lambda \mathrm{t} . \exists \mathrm{t}^{\prime}: \mathrm{t}^{\prime} \supseteq \mathrm{t} \& \mathrm{P}\left(\mathrm{t}^{\prime}\right)=1 \\
& \llbracket \mathrm{Imp}_{\mathrm{pl} 1} \rrbracket=\lambda \mathrm{P}_{\mathrm{pl}} \cdot \lambda \mathrm{t} . \exists \mathrm{t}^{\prime}: \mathrm{t}^{\prime} \supseteq \mathrm{t} \& \mathrm{P}\left(\mathrm{t}^{\prime}\right)=1
\end{aligned}
$$

Now, logical forms containing $I m p_{s g}$ can only express that an event, but not a sequence of events, is ongoing. On the other hand, logical forms with $\operatorname{Imp} p_{p l}$ can only express that sequences of events are ongoing.

My suggestion is that the so-called progressive or continuous readings of imperfective sentences are derived from logical forms like (23), and that habitual readings are derived from logical forms like (24). Thus, as far temporal semantics is concerned, continuous and habitual sentences are nearly synonymous, their logical forms differing minimally, and only with respect to the number specification of the VPs that combine with Imp. At this point, I beg the reader to disregard issues concerning modality. I will discuss those issues in detail in the next section, where I will supplement the meaning of $\operatorname{Imp}$ with quantification over possible worlds. As will become clear, I will try to argue that both continuity and habituality involve the same kind of modality. In this way, what I presented above can be seen as a first step towards a unified semantics for the continuous and habitual readings associated with imperfectivity. However, before we enter the modal domain, I want to present some empirical data illustrating the view I am advocating here.

\section{Crosslinguistic Data}

According to what we saw in the previous section, sensitivity to number leads us to expect the existence of three different imperfective operators: Imp, Imp $\operatorname{Isg}_{\text {sg }}$ and Imp $\mathrm{pl}_{\mathrm{pl}}$. Imp combines with both singular and plural VPs; Imp $\mathrm{p}_{\mathrm{sg}}$ combines only with singular VPs and Imp $p_{p l}$ combines only with plural VPs. The sensitivity to number that I am proposing for these temporal operators is similar to what happens in the nominal domain, where we find determiners like some, which combines with both singular and plural noun phrases ('some boy/some boys), every, which combines only with singular noun phrases ('every boy/*every boys), and all, which only combine with plural noun phrases ('*all boy/*all boys). In this section, I argue that all three imperfective operators are attested in natural language. 
Simple present sentences with accomplishments and activities in English and Portuguese, as illustrated in (27) below, give rise to habitual readings only, suggesting that $I m p_{p l}$, in this case a phonetically null operator, is part of their logical forms.
a. Mary dyes her hair.
b. A Maria tinge o cabelo.

Simple present sentences in Italian, French and Spanish are ambiguous between continuous and habitual readings, suggesting that both $I m p_{s g}$ and $I m p_{p l}$ are available for these languages. ${ }^{9}$ The same is true of another well-known construction in Romance, namely, the past imperfect, as illustrated in (28). ${ }^{10}$

$$
\begin{array}{llllll}
\text { A } & \text { Maria } & \text { tingia } & \text { o } & \text { cabelo. } & \text { (Port.) } \\
\text { THE } & \text { MARY } & \text { DYE.PAST-IMP } & \text { THE } & \text { HAIR } & \\
\text { 'Mary was dying/used to dye her hair.' }
\end{array}
$$

In fact, a similar ambiguity is attested in several other languages as well (Dahl (1985); Dahl (1995)), and, according to what I suggested above, it reduces to the possibility of Imp combining with both singular and plural VPs ${ }^{11}$. Finally, earlier stages of Turkish provide an example of a morpheme instantiating $\operatorname{Im} p_{s g}$ :

mektup yazyor 'he is writing letters'

According to Dahl (1995:418), "relatively recently, the -yor forms seem to have had progressive meaning only."

In conclusion, the analysis defended here provides a simple account of crosslinguistic variation within the domain of imperfectivity, reducing the differences to a single parameter related to the 'number' requirements of a (existential) aspectual operator.

\section{Imperfectivity and Modality}

In the previous sections, by focusing the discussion on issues concerning temporal semantics, I neglected an important component in the meaning of imperfective sentences. It is now time to revise it. Let us start by looking at continuous readings, exemplified here by the English progressive. I will call the aspectual operator present in these sentences Prog. Since, for the moment, we will only be dealing with continuous readings, the meaning of Prog will be the meaning we assigned to $I m p_{s g}$ before. According to the lexical entry of this aspectual operator, a sentence of the form [ $T$ Prog VP] entails the existence of a singular time interval at which an event of the type described by the VP takes place. However, as has been acknowledged in the literature since the seventies, this seems to be too strong, as attested by examples like (30) below: 
(30) can be true even if John has never finished building a house. It seems that it is enough that he was in the process of building one for the sentence to be true. This intuition is corroborated by examples like the following:

John was crossing the street (when a bus hit him).

Again, for (31) to be true, all we have to check is whether or not John had started walking toward the other side of the street, when the bus hit him. What is interesting about this case is that the sentence can be true even if, when John started crossing the street, the likelihood that he was going to finish it was very low, for instance, if the traffic was heavy, cars were running fast, and the pedestrian light was red. Thus, it appears that external obstacles, no matter how likely they are to interfere in the ongoing event, are not taken into account when we assess the truth of (31). By external obstacles, I mean people or objects other than John and the street he was crossing.

What happens when an event is interrupted not by an external obstacle, but by the limitations of one of the participants of the event? Consider a variation of (31) (due to Fred Landman):

John was crossing the Atlantic.

Imagine (32) being uttered five minutes after John started swimming on the West Coast of Africa towards the Brazilian Coast on the other side of the Atlantic. This sentence is very likely to be judged false, and, apparently, the reason for that is the fact the Atlantic is a huge portion of water, and the John that we have in mind is probably a normal human being. Since any human being would give up or die before being even close to Brazilian waters, the fact that our John had started swimming before the reference time (five minutes after he started in the scenario above) is not enough to make the sentence true. Contrary to the buses and cars in the case of (31), the relevant obstacle here has to do with John's physical conditions and, also, the size of the Atlantic. On the other hand, if John is known to have supernatural powers, judgments change, and the sentence is considered appropriate to describe the situation. These facts tell us that progressive sentences with accomplishment VPs can be false, even when the process constituting the event being described by the sentence is already going on.

When animate participants are involved, not only their physical conditions, but also their mental state seem to matter. Consider (31) again, but this time uttered under different circumstances. Imagine John is standing on one side of the street when he sees a one hundred dollar bill right in the middle of the street. He then starts walking there to pick up the bill, when a bus comes and hit him. (31) is judged false in this case, and this can only be due to the fact he did not intend to cross the street, since apart from that, the scenario is identical to the other one we discussed above in connection to the very same sentence. 
What is needed then is a supplement to our current lexical entry for Prog that takes into account the facts discussed above. In this section, I will present Paul Portner's modal analysis of the progressive (Portner (1998)), which has its roots in the influential work by David Dowty back in the seventies (Dowty (1977)). After showing how his analysis of Prog can handle the relevant facts, I will argue that habitual readings can be analyzed along the same lines, once we maintain the unified temporal treatment of habituals and progressives proposed in the previous section. The final result will be a complete unification (temporal and modal) between these two notions.

\subsection{Portner (1998): the progressive in modal semantics}

Portner's background is Angelika Kratzer's semantics for modality (Kratzer (1981)), which has three crucial ingredients: a quantifier over possible worlds, a modal base, and an ordering source. Given a world $w$ (the world of evaluation), the modal base $(M)$ provides a set of propositions $M(w)$, which constrain the set of worlds that are being quantified over. Only worlds in which every proposition in the set provided by the modal base is true $(\cap \mathrm{M}(\mathrm{w}))$ are relevant for the interpretation of the sentence. The ordering source $(O)$ also provides a set of propositions $(O(w))$, a set understood as an ideal according to which worlds can be ranked. A world $w^{\prime}$ is at least as close to the ideal as world $w^{\prime \prime}$ ( $w^{\prime} \leq_{\mathrm{O}} w^{\prime \prime}$ ) if, and only if, every proposition that is true in $w^{\prime}$ is also true in $w^{\prime \prime}$. The core feature of the proposal is that, when evaluated with respect to a world $w$, quantification is restricted to the worlds belonging to $(\cap \mathrm{M}(\mathrm{w}))$ that are ranked best according to $O(w)$ (Best $\mathrm{M}, \mathrm{O}, \mathrm{w})$. Crucially, choices of modal bases and ordering sources vary from context to context, being usually determined by both linguistic and extralinguistic material.

Portner's proposal is to analyze the meaning of progressive sentences as involving universal modal quantification, along the lines summarized above. The question then is what kinds of modal base and ordering sources are involved in these sentences. His suggestion is that the modal base is a variety of circumstantial one, and that the ordering source is based on the ideal that the event described by the sentence (under VP) is not interrupted by any 'outside' factor. Let us consider the example he used to illustrate what he has in mind:

Mary was climbing Mount Toby.

Circumstantial modal bases take into consideration what the relevant facts are in a certain context The modal base for (33) would deliver a set of propositions, expressing the relevant facts about Mary's current physical and mental conditions (her strength, her age, her dispositions, etc...), Mount Toby's physical state (its height, its soil, its shape, etc ..), and also what Mary is doing (Has she started climbing MT? Is she heading the right way? Is she lost?). This set might look like (34) below: 
$\mathbf{M}(\mathrm{w})=\{$ 'Mary is in good physical condition', 'Mary does not give up easily', 'It was raining lightly on Mount Toby at 7', 'Mary was headed the right way on the trail at $7, \ldots\}$

Given the circumstances above, (33) is intuitively true. However, notice that among the worlds in which every proposition in (34) is true, there are worlds in which Mary will never manage to climb MT. Think about worlds in which she gets eaten by a bear, or in which she slips and gets seriously injured. Things like that are not necessarily uncommon when people climb mountains, especially if they are not professionals. However, the possibility that these events happen seems to be irrelevant when computing the truth-conditions for (34). That is when the ordering source enters the scene in Portner's analyses. In the case of (34), it would look something like (35):

$\mathrm{O}(\mathrm{w})=\{$ 'Mary does not get eaten by a bear', 'Mary does not slip and hurt her ankle', 'A surprise summer blizzard does not start on MT', 'Mary does not get lost', ...

Together, the propositions in (35) express an ideal set of worlds in which Mary encounters no obstacle in her way towards the top of MT. In a sense, in these worlds (the worlds in $\cap \mathrm{O}(\mathrm{w})$ ), whether or not Mary manages to climb MT depends exclusively on how they look like at the relevant time.

According to (34) and (35), Best (M, O, w) contains all the worlds in which Mary and Mount Toby are similar to what they are in the actual world at the relevant time, and no outside factors like bears, rocks, blizzards interrupt the climbing. The idea is that (33) will be true just in case all such worlds are ones in which Mary climbs Mount Toby. Under the circumstances in (34), (33) is predicted to be true. On the other hand, if it is snowing heavily on MT, the proposition 'It was raining lightly on MT' would be replaced by 'It is snowing heavily on $\mathrm{Mt}^{\prime}$ ' in $\mathrm{M}(\mathrm{w})$. Now, Mary could never make it to the top, even if she tries hard. In this case, Best $(\mathrm{M}, \mathrm{O}, \mathrm{w})$ would contain worlds in which Mary does not climb MT, and the sentence is predicted to be false. Both predictions are borne out.

At this point, it should be clear how Portner's theory could handle the puzzling contrast between (31) and (32), discussed in the beginning of this section. It is clear from what we saw above that both the modal base and the ordering source depend on the description of the event under VP. Thus, in the case of (31), M(w) includes all the relevant facts about John and the street he is crossing, whereas in the case of (32), it includes all the relevant facts about John and the Atlantic Ocean, including the fact that it is a huge portion of water. In this case, even if we restrict attention to worlds in which all potential obstacles for the completion of an event of John crossing the Atlantic were removed (no sharks, no unexpected storms, etc ...), given John's limited physical conditions, and the size of the ocean, most, if not all, worlds in this set would be worlds in which he fails to cross the Atlantic. Accordingly, the sentence is judged false. In the case of (31), if the street is an average street, e.g. if it is $\mathbf{3 0}$ feet large, then this information is 
part of $\mathrm{M}(\mathrm{w})$. Since John will manage to cross the street in all of then, as soon as we remove the external obstacles (oncoming buses, cars running fast, etc ...), the sentence is predicted to be true, the correct result. below $^{12}$ :

The new lexical entry for Prog that emerges from this discussion is given

$\llbracket \operatorname{Prog} \rrbracket^{w}=\lambda \wp_{<w, i t>} \lambda t$. for every world w' in $\operatorname{BEST}(M, O, w, t)$, there is a time interval $\mathrm{t}^{\prime}$, such that $\mathrm{t} \subseteq \mathrm{t}^{\prime}$, and $\wp\left(\mathrm{w}^{\prime}\right)\left(\mathrm{t}^{\prime}\right)=1$.

(37) $\operatorname{BEST}(\mathrm{M}, \mathrm{O}, \mathrm{w}, \mathrm{t})=$ the set of worlds $\mathrm{w}^{\prime}$ in $\cap \mathrm{M}(\mathrm{w}, \mathrm{t})$, such that there is no world w' in $\cap M(w, t)$ where $w$ "'< $O(w, t) w '$.

Notice that the first argument of Prog in (36) is the intension of a VP denotation, a function from worlds to sets of time intervals. I also added an extra argument for BEST, which captures the fact that the set of propositions delivered by the modal base and the ordering source is sensitive not only to the world of evaluation, but also to what is usually called the reference time. Modal bases and ordering sources change as time goes by. For instance, for a sentence like 'At three o'clock, Mary was climbing Mount Toby', what counts as relevant is not Mary's physical conditions when she was a young child, or how tall Mount Toby was during the Paleolithic. On the contrary, it is their conditions at three o'clock that matters.

\subsection{Integrating habituality into the picture}

According to what I said in previous sections, habitual and continuous readings of imperfective sentences share the same temporal semantics. I argued there that the difference between those readings come from a difference concerning the plurality of the time intervals being quantified over, singular intervals in the case of continuous readings, plural intervals in the case of habituals. We have just seen that progressive sentences expressing continuous readings have also a modal component. I will now argue that habitual readings share the same modal component, thus maintaining the view that continuous and habitual readings have the same source (modulo number specification), namely, Imp morphemes: Imp, $I m p_{S G}$ and $I m p_{P L}$.

Consider the following scenario: John, who loves soccer, does not live far from college, where the only soccer field in the neighborhood is located. He goes there regularly to play with his friends. Sentence (38) below is true under these circumstances:

John plays soccer.

(38) tells us something about John's current dispositions. Unless some external factor interferes, he will walk to the campus and play soccer again in the future, as he has been doing for a while. The proviso 'unless some external factor interferes' is crucial since a speaker who utters (38) does not commit himself to the existence 
of future events of John playing soccer, regardless of what might happen to John. Thus, if John suddenly dies before tomorrow morning, of course, he will never walk to the campus again, let alone play soccer. Also, if tomorrow John gets a message saying that the campus has closed, and that all departments and facilities, including the soccer field, are being transferred to another location, which happens to be 10 miles away from John's house, he will probably stop playing soccer. But these possibilities do not interfere in the truth of (38). In assessing the truth of (38), we seem to ignore all possible interruptions of a current sequence of events of John playing soccer. In fact, sentences like (39) can perfectly be true:

John used to play soccer, when he died.

Notice the striking similarity between what we saw before in the case of continuous readings of progressive sentences, and what we have just seen above with respect to habitual readings. In particular, compare our discussions of (31), 'John was crossing the street', and (38). In the former, we discarded all potential external obstacles to the completion of a singular event, whereas in the latter we discarded all potential obstacles to the continuation of a sequence of events, which, according to our previous discussions, is nothing but a plural event. Since the singular/plural distinction was factored out from the meaning of $\operatorname{Imp}$, it is natural to conclude that the modal component integrated into the meaning of Imp/Prog discussed in relation to continuous readings carries over to the cases involving habitual readings as well. In other words, the logical forms associated with continuous and habitual readings of imperfective sentences are identical, except for the number specification of the aspectual operator Imp.

Before I go through the details of these logical forms, and discuss some important consequences, let me present another fact that strengthens the parallel between continuous and habitual readings. Recall Landman's discovery that in the case of sentences like (32), 'John was crossing the Atlantic', which are judged false if John is not a superhero, what is crucial is the fact that John's physical conditions, and the Atlantic's huge dimensions make it impossible for him to cross the ocean, even if we grant that external obstacles are going to be removed. Thus, in this case it is not enough that John believes he can cross the Atlantic, and intends to do so. The conclusion was that the actual physical features of the participants in the events described under VP are also taken into account by the circumstantial modal base. Are there similar situations involving habituality? I believe there are. Consider the following cartoonlike scenario: One of the hobbies of a certain superhero is to cross the Atlantic to keep his shape. However, yesterday night, while he was sleeping, he lost his superpowers forever, and became a normal human being. He does not know that, so tomorrow morning he will wake up and prepare for his exercise, just like he does every day. Now, sentence (40) below is not judged true, despite the fact that the superhero's dispositions have not changed.

The superhero crosses the Atlantic. 
As in the previous case, the relevant circumstances here take into consideration physical facts about the superhero and the ocean, and that is why the sentence is judged false. Thus, we seem to be dealing with the same kind of circumstantial modal base that Portner proposed for the continuous readings of progressive sentences.

I will assume that is the case, and propose the (simplified) logical form in (41)for the habitual reading of sentence (38):

[TP Pres PAspP Impl $_{\mathrm{pl}}$ [VP-pl pl [vP John play soccer ]]]]

The truth-conditions are given below:

$\llbracket \mathrm{TP} \rrbracket^{\mathrm{w}}=1$ iff for every world $\mathrm{w}^{\prime}$ in $\operatorname{BEST}(\mathrm{M}, \mathrm{O}, \mathrm{w}, \mathrm{t})$, there is a plural time interval t', such that $T U \subseteq \mathrm{t}^{\prime} \&$ PLAY_SOCCER(j, t').

First, imagine (38) uttered at a time before the campus was closed. The set of worlds yielded by the circumstantial modal base $\mathbf{M}$ at that time would look like (43) below:

(43) $\quad M(w, t)=\{$ John played soccer with his friends several times recently, John is in good physical conditions, John intends to play soccer again, there is a soccer stadium close to John's house, ...

(43) contains relevant information about John's physical and mental states at the utterance time, about the existence of a stadium in the neighbohood, and also about past occurrences of John playing soccer. I assume these are the minimal relevant circumstances taken into consideration by the modal base in simple habitual sentences. What about the ordering source? The propositions in the set delivered by the ordering source $\mathrm{O}$ encode the conditions for a sequence of events of the type described under VP not interrupt. In our case we have something along the lines of (44):

$\mathrm{O}(\mathrm{w}, \mathrm{t})=\{$ John does not die tomorrow, John does not get arrested, the stadium does not close, ... $\}$

The set BEST (M, O, w, t) will then consist of the worlds in $\cap \mathrm{M}(\mathrm{w}, \mathrm{t})$ which rank best according to $\mathrm{O}(\mathrm{w}, \mathrm{t})$. (42) requires that there be a plural time interval at which John plays soccer in all these worlds. This plural interval should include the time of utterance. As a result, if John does not happen to be playing soccer right at the utterance time, (42) requires the existence of both past and future singular intervals at which John plays soccer. In our case, since $\mathrm{M}(\mathrm{w}, \mathrm{t})$ and $\mathrm{O}(\mathrm{w}, \mathrm{t})$ are consistent, BEST will contain worlds in which John keeps playing soccer. Therefore, the existence of future playing events in these worlds is guaranteed. As for past events, since the modal base cares about whether or not there were previous playing events in the world of evaluation, and in our scenario there were, the worlds in BEST are also worlds in which there was at least one event of John 
playing soccer before the utterance time. Thus, (38) is correctly predicted to be true under the circumstances we are considering. Notice that the sentence would be false if John had never played soccer before the utterance time. Since $M(w, t)$ would contain this information, there would never be a plural interval that included the utterance time in the worlds in BEST, at which John played soccer. I believe this is correct. If John had never played soccer before the utterance time, then (38) is not true.

Imagine now that John cannot control the movements of his legs anymore due to a tragic car accident, and that (38) was uttered after these facts became known. This crucial aspect of the new scenario has a direct impact on $M(w, t)$ :

$\mathrm{M}(\mathrm{w}, \mathrm{t})=\{$ John played soccer with his friends several times recently, John cannot move his legs, there is a stadium close to John's house, ... $\}$

Given (45), the worlds in BEST are not worlds in which there are future events of John playing soccer. As a consequence, they are not worlds in which there is a plural interval that includes the utterance time at which John plays soccer. (38) is correctly predicted to be false in this case.

Summarizing, habitual readings of imperfective sentences can be analyzed as involving the same kind of modality observed in connection to continuous readings. Since their temporal components are also the same, we arrive at a unified semantics for the aspectual operators involved in imperfective sentences. The origin of the ambiguity lies elsewhere, in the number of the VP-predicate with which the operator combines: singular in the case of continuous readings, plural in the case of habitual readings. The same is true of the other instances of imperfectives that we mentioned before, such as the past imperfect in Romance. ${ }^{13}$

\section{Conclusion}

This paper was an attempt to provide a unified semantics for continuous and (simple) habitual readings of imperfective sentences. Based on a structured temporal domain, containing both singular and plural intervals, I argued that the only difference between continuous and habitual readings concerns the number (singular or plural) of the time intervals that are quantified over in the logical form of the sentences. I proposed that the source of imperfectivity is an aspectual operator, which introduces existential quantification over time intervals and universal quantification over possible worlds. We went through several cases suggesting that both readings involve the same kind of modality, one that involves a circumstantial modal base and an ordering source based on an ideal in which an ongoing event of the kind described by the sentence is not interrupted by external factors, as proposed by Portner (1998) for the English progressive. I argued that the difference between continuous and habitual readings is related to the fact that in the former it is singular 'events' (more precisely, singular time intervals) that are not interrupted, whereas in the latter it is plural ones that are not. I looked at different imperfective operators in Romance and English, and concluded we can 
reduce the difference between them to the number specification restricting the kinds of intervals they can quantify over, in a way that is very similar to what happens with determiners in the nominal domain.

\section{Endnotes}

* I would like to express my gratitude to the following people who helped me with their comments and criticism during the elaboration of this paper: Kai von Fintel, Danny Fox, Elaine Grolla, Irene Heim, Sabine Iatridou, Michael Kenstowicz, and Ken Wexler. Special thanks to Irene Heim for support and encouragement.

${ }^{1}$ Dowty (1977), Landman (1992), and Portner (1998) are among the works that have undertaken this task. See also Bonomi (1997a) for an event-based analysis that share some of the ideas developed by those authors. For a different view on the matter, cf. Vlach (1981), Bach (1986) and Parsons (1990).

${ }^{2}$ But see Krifka (1987) and Krifka (1988) for suggestions.

3 The sentences in (6) differ from sentences like 'John sells vacuum cleaners' or 'This machine crushes oranges', which I take to involve tripartite structures, the restrictor in this case, being a set of situations pre-specified in a job contract or in an owner's manual for example.

${ }^{4}$ Linking habituality to modality is, of course, not so surprising, since it has often been remarked about habitual statements that they convey more than pure repetitions of a certain situation. On a pair with generic sentences, they have been said to express non-accidental, lawlike statements. See Krifka et al. (1995) and references therein. I will return to the modal ingredients of habituals in section 6.

${ }^{5}$ For different unifying ideas, which I will not be able to review here, see Bonomi (1997b), and Cipria and Roberts (2000).

6 I will rely on the one-to-one correspondence between sets and their characteristic functions, and use the terms interchangeably throughout the paper.

${ }^{7}$ I will follow the tradition inaugurated with Partee (1973), according to which tenses are treated as pronouns. Thus, when not bound by an operator, $T$ nodes refer to context salient time intervals. Distinctions among tenses, e.g. past vs. present can be encoded as presuppositions in their lexical entries. Following the notational conventions in Heim and Kratzer (1998), lexical entries of tenses would look like the following:

(i) $\quad$ [ past $_{1} \rrbracket^{\mathrm{g}}=\mathrm{g}(1)$ if $\mathrm{g}(1)$ precedes the utterance time; and undefined otherwise.

(ii) $\llbracket$ pres $_{1} \rrbracket^{\mathrm{g}}=\mathrm{g}(1)$ if $\mathrm{g}(1)$ is the utterance time; and undefined otherwise.

For our purposes, $\mathrm{g}$ can be viewed as a function provided by the context of utterance, mapping indices to contextually salient entities.

${ }^{8} \mathrm{~A}$ parallel with the nominal domain will be discussed in the next section.

9 I will not discuss simple present sentences with stative predicates, such as 'John is sick'. These sentences do not have habitual interpretations. All they mean is that a certain sate holds at the utterance time. One idea that comes to mind is that they involve bare VPs directly connected to tense, without mediation of an aspectual layer. I will leave these issues for another occasion. For an analysis, see 
Swart (1998), whose key ingredient is a mechanism of coercion, which inserts a habitual (iterative) operator in the logical form of simple present sentences with accomplishments and activity predicates, but not with statives.

${ }^{10}$ As its name suggests, the past imperfect is an aspectual operator used only in combination with the past tense. I will encode this restriction in its lexical entry, by means of a logical presupposition (the notation is from Heim and Kratzer (1998)).

(i) $\quad \llbracket$ Past Imp $\rrbracket^{g}=\lambda P_{<i \downarrow} . \lambda t: t<g(0) . \exists t^{\prime}: t^{\prime} \supseteq t \& P\left(t^{\prime}\right)=1$

In (i), $O$ is a designated index, which the assignment $g$ always maps to the utterance time. After 【Past Imp】 combines with its first argument, the result is a function from intervals to truth values. The formula after the colon indicates that this function is a partial function, only defined for past intervals.

11 The progressive in English and Portuguese also gives rise to continuous and habitual readings, although the use of progressive sentences to express habituality is limited to recently acquired habits in both languages. As for other Romance languages, one finds a lot of dialectal variation concerning geographical and social factors. For data and discussion, see Squartini (1998) and the references cited there.

${ }^{12}$ This is not exactly what Portner gives, since his analysis is couched within an event-based framework.

${ }^{13}$ With the possible exception of Italian, whose Imperfect has been claimed to lack a modal component. Cf. Giorgi and Pianesi (1998).

\section{References}

Bach, Emmon. 1986. The Algebra of Events. Linguistics and Philosophy 9:5-16. Bonomi, Andrea. 1997a. The Progressive and the Structure of Events. Journal of Semantics 14:173-205.

Bonomi, Andrea. 1997b. Aspect, Quantification and When-clauses in Italian. Linguistics and Philosophy 20:469-514.

Cipria, Alicia, and Craige Roberts. 2000. Spanish Imperfecto and Preterito: Truth Conditions and Aktionsart Effects in a Situation Semantics. Natural Language Semantics 8:297-347.

Cohen, Ariel. 1999. Think Generic: The Meaning and Use of Generic Sentences. Stanford: CSLI.

Dahl, Östen. 1985. Tense and aspect systems. New York: B. Blackwell.

Dahl, Östen. 1995. The Marking of the Episodic/Generic Distinction in TenseAspect Systems. In The Generic Book, eds. Gregory N. Carlson and Francis Jeffry Pelletier, 412-425.

Dowty, David. 1977. Toward a Semantic Analysis of Verb Aspect and the English 'Imperfective' Progressive. Linguistics and Philosophy 1:45-77.

Giorgi, Alessandra, and Fabio Pianesi. 1998. Tense and Aspect. New York: Oxford University Press. 
Greenberg, Yael. 2003. Manifestations of Genericity: Outstanding Dissertations in Linguistics. New York \& London: Routledge.

Heim, Irene, and Angelika Kratzer. 1998. Semantics in generative grammar: Blackwell textbooks in linguistics ; 13. Malden, Mass.: Blackwell.

Klein, Wolfgang. 1994. Time in language: Germanic linguistics. London ; New York: Routledge.

Kratzer, Angelika. 1981. The Notional Category of Modality. In Words, Worlds, and Contexts: New Approaches in Word Semantics, eds. Hans-Jürgen Eikmeyer and Hannes Rieser, 38-74.

Krifka, Manfred. 1987. An Outline of Genericity: Technical Report SNS-Bericht 87-125, Tübingen University.

Krifka, Manfred. 1988. The Relational Theory of Genericity. In Genericity in Natural Language: Proceedings of the 1988 Tübingen Conference, ed. Manfred Krifka, 285-311.

Krifka, Manfred et al. 1995. Genericity: An Introduction. In The Generic Book, eds. Gregory Carlson and Francis Jeffrey Pelletier, 1-124. Chicago: The University of Chicago Press.

Landman, Fred. 1992. The Progressive. Natural Language Semantics 1:1-32.

Parsons, Terence. 1990. Events in the semantics of English : a study in subatomic semantics: Current studies in linguistics series ; 19. Cambridge, Mass.: MIT Press.

Partee, Barbara. 1973. Some Structural Analogies between Tenses and Pronouns in English. Journal of Philosophy 70:601-609.

Portner, Paul. 1998. The Progressive in Modal Semantics. Language 74:760-787.

Squartini, Mario. 1998. Verbal Periphrases in Romance: Aspect, Actionality, and Grammaticalization. Berlin: Mouton de Gruyter.

Swart, Henriette de. 1998. Aspect Shift and Coercion. Natural Language and Linguistic Theory 16:347-385.

Vlach, Frans. 1981. The Semantics of the Progressive. In Tense and Aspect, eds. Philip Tedeshi and Annie Zaenen, 271-292. New York: Academic Press. 